University of Wollongong

Research Online

Faculty of Engineering - Papers (Archive)

Faculty of Engineering and Information

Sciences

$1-1-2012$

\title{
Hot deformation of cast and extruded TiAl: An in-situ diffraction study
}

Thomas Schmoelzer

Montanuniversitat Leoben

Klaus-Dieter Liss

Australian Nuclear Science and Technology Organisation, Klaus-Dieter.Liss@ansto.gov.au

Svea Mayer

Montanuniversitat Leoben

Kun Yan

University of Wollongong, ky241@uowmail.edu.au

Mark H. Reid

University of Wollongong, mreid@uow.edu.au

See next page for additional authors

Follow this and additional works at: https://ro.uow.edu.au/engpapers

Part of the Engineering Commons

https://ro.uow.edu.au/engpapers/5319

\section{Recommended Citation}

Schmoelzer, Thomas; Liss, Klaus-Dieter; Mayer, Svea; Yan, Kun; Reid, Mark H.; Dippenaar, Rian J.; Peel, Matthew; and Clemens, Helmut: Hot deformation of cast and extruded TiAl: An in-situ diffraction study 2012, 1725-1730.

https://ro.uow.edu.au/engpapers/5319

Research Online is the open access institutional repository for the University of Wollongong. For further information contact the UOW Library: research-pubs@uow.edu.au 


\section{Authors}

Thomas Schmoelzer, Klaus-Dieter Liss, Svea Mayer, Kun Yan, Mark H. Reid, Rian J. Dippenaar, Matthew Peel, and Helmut Clemens 


\title{
Hot Deformation of Cast and Extruded TiAl: An In-situ Diffraction Study
}

Thomas Schmoelzer ${ }^{1, a}$, Klaus-Dieter Liss ${ }^{2, b}$, Svea Mayer ${ }^{1, c}$, Kun Yan ${ }^{2,3, d}$, Mark Reid $^{3, e}$, Rian Dippenaar ${ }^{3, f}$, Matthew Peel ${ }^{4,9}$ and Helmut Clemens ${ }^{1, h^{\prime}}$

${ }^{1}$ Department of Physical Metallurgy and Materials Testing, Montanuniversität Leoben, Franz-JosefStraße 18, 8700 Leoben, Austria.

${ }^{2}$ Australian Nuclear Science and Technology Organisation, NSW 2234, Lucas Heights, Australia.

${ }^{3}$ Faculty of Engineering, University of Wollongong, NSW 2522, Wollongong, Australia.

${ }^{4}$ European Synchrotron Radiation Facility, BP 220, 38043 Grenoble, France.

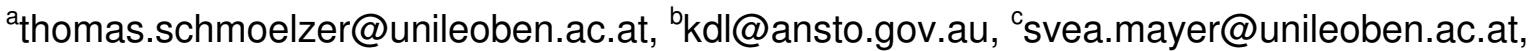
dkuy@ansto.gov.au, ${ }^{\mathrm{d}} \mathrm{mhr02@uow.edu.au,}{ }^{\mathrm{f}}$ rian@uow.edu.au, ${ }^{9}$ matthew.peel@bristol.ac.uk, helmut.clemens@unileoben.ac.at

Keywords: Titanium aluminides. recovery, recrystallization, hot deformation, extrusion, casting, Xray diffraction

\begin{abstract}
Intermetallic TiAl alloys are a class of innovative high-temperature materials which are developed to replace the substantially denser Ni-base alloys in low-pressure turbine blades of jet engines. By streamlining the production process of these parts, a substantial decrease in production costs can be achieved. To this end, a profound knowledge of the microstructural processes occurring during hot deformation is a prerequisite. To investigate the microstructural development during forming operations, cast and extruded as well as only cast specimens were hot-deformed and the microstructural development investigated in-situ by means of a novel diffraction method. This powder diffraction method utilizes the behavior of individual reflection spots on the Debye-Scherrer rings for deriving the materials response to the deformation imposed. It was found that the behavior of the two specimens is rather similar, although the starting microstructures show pronounced differences.
\end{abstract}

\section{Introduction}

Titanium aluminide alloys are structural materials that consist of intermetallic phases which are ordered at room temperature. One targeted area of application for this type of materials are blades in the low-pressure turbine of jet engines where they could replace $\mathrm{Ni}$ based alloys and thereby contribute to a substantial weight reduction [1-3]. For a successful introduction to the market, cost effective production routes are a prerequisite. Profound knowledge of the materials behavior during hot-deformation is necessary for streamlining the production process.

In-situ diffraction experiments were performed using a high-energy beamline of a synchrotron facility to investigate the different behavior of cast and extruded and only cast specimens during hot deformation. Starting microstructures of the two specimens are notably different due to the deviating production routes. The experimental technique used is described extensively in [4] while it will be recapitulated here only briefly.

In principle, a powder diffraction experiment is conducted while the specimen is deformed. Since only a limited number of crystallites are illuminated, single diffraction spots are discernible on the Debye-Scherrer rings which are recorded by a fast area detector with a frame rate of about $2 \mathrm{~Hz}$. To highlight the behavior of grains over time, azimuthal-angle time plots (AT-plots) are established. In these, the intensity of a single reflection of a phase is plotted as a function of azimuthal angle and time. For details concerning the assembly of an AT-plot see [5].

The results of this method combined with those of complementary investigations, aiming to characterize the fine scale microstructure, offer new insights concerning the processes occurring during high temperature deformation of TiAl alloys. 


\section{Experimental}

Cast material was supplied by GFE Metalle und Materialien GmbH, Nuremberg, Germany, with chemical compositions of Ti-44.17 Al-4.23 Nb-1.06 Mo-0.13 B (alloy A) and Ti-43.7 Al-3.88 Nb$0.97 \mathrm{Mo}-0.1 \mathrm{~B}$ (in at\%) (alloy B). Further information concerning these so-called TNM alloys is given in [6,7]. Subsequently to casting, a hot isostatic pressing (HIP) process was performed at $200 \mathrm{MPa}$ and $1200{ }^{\circ} \mathrm{C}$ for $4 \mathrm{~h}$. After that, only alloy B was extruded to refine the cast microstructure. Specimens were prepared from the material before and after the extrusion process.

In-situ diffraction experiments were conducted at beamline ID15b of the European Synchrotron Radiation Facility in Grenoble, France with a monochromatic X-ray beam having a mean energy of $86.9 \mathrm{keV}$ and a cross section of $0.1 \times 0.1 \mathrm{~mm}^{2}$ at the sample position [8]. An Instron (Norwood, USA) electro thermomechanical tester (ETMT) was used for heating and compressing the cylindrical specimens which had a diameter of $4 \mathrm{~mm}$ and a height of $8 \mathrm{~mm}$. The specimens were heated resistively while temperature control was achieved by means of a type $S$ thermocouple spot welded to the specimen surface. A Thales Pixium 4700 (Thales Group, Neuilly-sur-Seine, France) flat panel detector was employed for recording the diffraction patterns at a frame rate of roughly $2 \mathrm{~Hz}[9]$.

The specimens were heated to a temperature of $1300{ }^{\circ} \mathrm{C}$ at a rate of $10{ }^{\circ} \mathrm{C} / \mathrm{s}$ and held at this temperature for $30 \mathrm{~s}$ before they were deformed. A constant anvil speed was adjusted in such a way that a mean true strain rate of $3.5 \times 10^{-3} 1 / \mathrm{s}$ was achieved. Deformation was carried out under isothermal conditions. However, due to the increase in cross section during compression, the electrical resistance of the specimen declined with increasing strain which caused the ETMT to reach its maximum heating power during the experiment. From this point on, a decrease in temperature could not be prevented.

Ex-situ experiments were performed to investigate the microstructure present immediately before deformation started. To this end, specimens were held at $1300{ }^{\circ} \mathrm{C}$ for $30 \mathrm{~s}$ and subsequently quenched with a Bähr DIL 805 dilatometer. Microstructural images where then obtained by means of a scanning electron microscopy (SEM). All SEM images were acquired with a Zeiss Evo 50 at an acceleration voltage of $20 \mathrm{keV}$ in back scattered electron (BSE) mode.

\section{Results and Discussion}

To characterize the material in the as-received condition, SEM investigations of specimens prepared by standard metallographic techniques were performed. Figure 1a features the cast microstructure after HIPing while in Figure $1 \mathrm{~b}$ the microstructure of the extruded specimen is presented. It is evident that the mean grain size of the extruded specimen is significantly smaller compared to the cast and HIPed condition. Furthermore, a pronounced elongation of the grains has occurred during extrusion. In both microstructures $\alpha_{2}\left(\mathrm{D} 0_{19}\right), \beta_{\mathrm{o}}(\mathrm{B} 2)$ and $\gamma\left(\mathrm{L} 1_{0}\right)$ phase are observed.
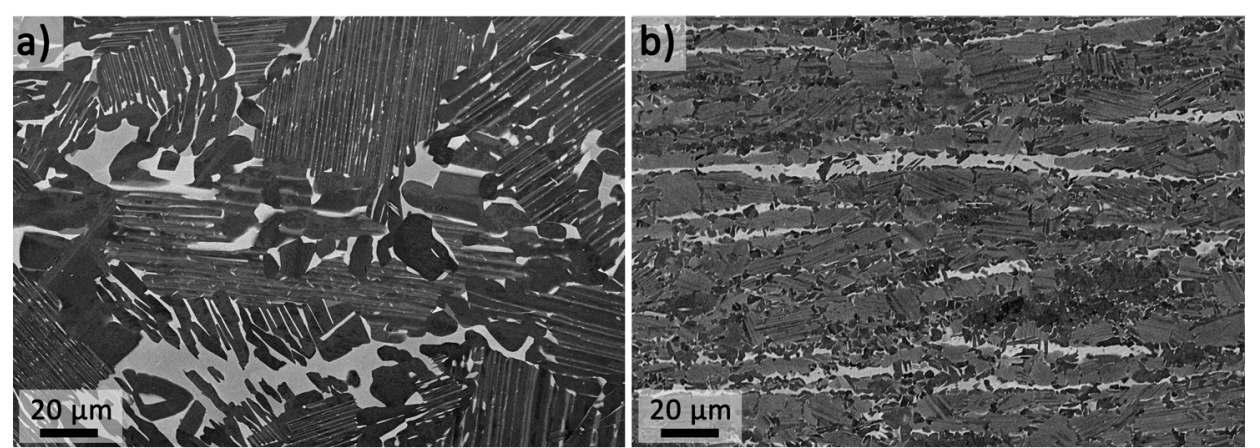

Fig. 1: The starting microstructures of the cast (a) and the extruded (b) material were imaged by SEM in BSE mode. In both images the phases $\beta_{\mathrm{o}}$ (light contrast), $\alpha_{2}$ (intermediate contrast), and $\gamma$ (dark contrast) are visible. In (b), the extrusion direction lies horizontally. 
The microstructure present after holding for $30 \mathrm{~s}$ at $1300{ }^{\circ} \mathrm{C}$ is shown in Figure 2. Figure $2 \mathrm{a}$ represents the HIPed specimen while Figure $2 b$ stems from the extruded sample. Compared to the images obtained in the as-received condition, the amount of $\beta_{0}$-phase has substantially increased in both specimens. It is important to note, that $\alpha_{2}$ and $\beta_{\mathrm{o}}$-phase are present in their disordered forms at $1300{ }^{\circ} \mathrm{C}$. Even upon rapid quenching, the phases order which is why only ordered phases are observed in the micrographs [4,6]. It is evident that the average grain size of $\alpha$ grains is smaller in the extruded sample compared to the cast specimen.
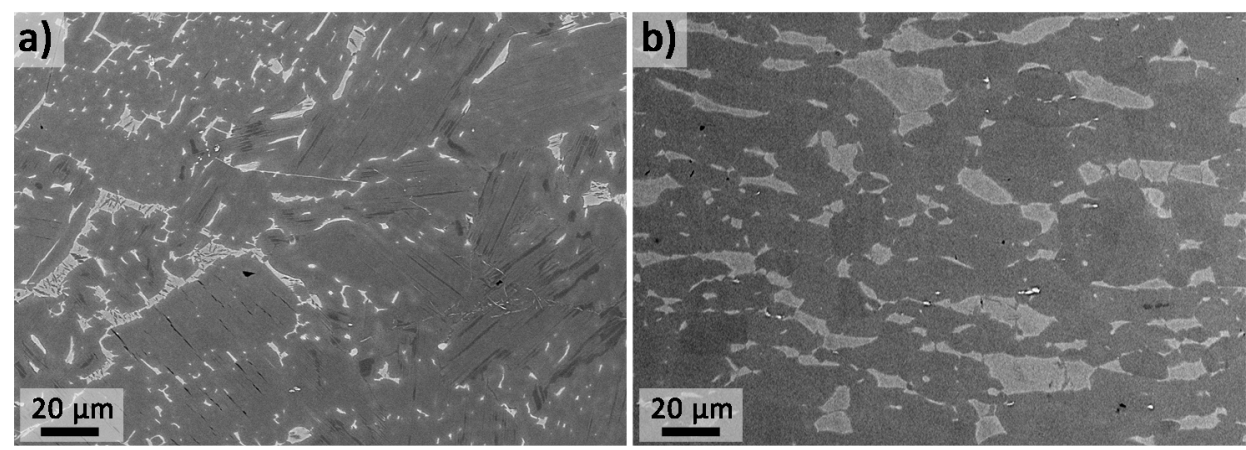

Fig. 2: Images of the microstructure after heating to $1300{ }^{\circ} \mathrm{C}$ and holding for $30 \mathrm{~s}$ and rapid quenching are shown. These images represent the state in which the cast (a) and the extruded (b) specimen were before compression took place. Images acquired by SEM in BSE mode. In (b) the extrusion axis lies horizontally.

Figure 3 shows images of the microstructure after hot deformation. In the cast specimen (Figure 3a) the bright $\beta_{0}$-phase and the darker $\alpha_{2}$-phase are discernible. Due to fast cooling from the

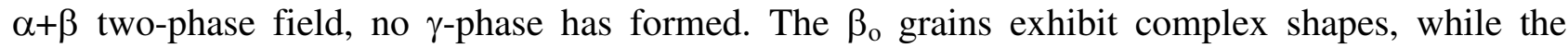
morphology of the $\alpha_{2}$ grains is hard to determine since hardly any grain boundaries are visible. In Figure $3 b$, the $\beta_{\mathrm{o}}$-phase grains are more spherical which is contrasted by the directional morphology of grains in Figure 3a. Additionally, the mean grain diameter perpendicular to the extrusion direction $(b$, inset) is smaller than that parallel to the extrusion axis.
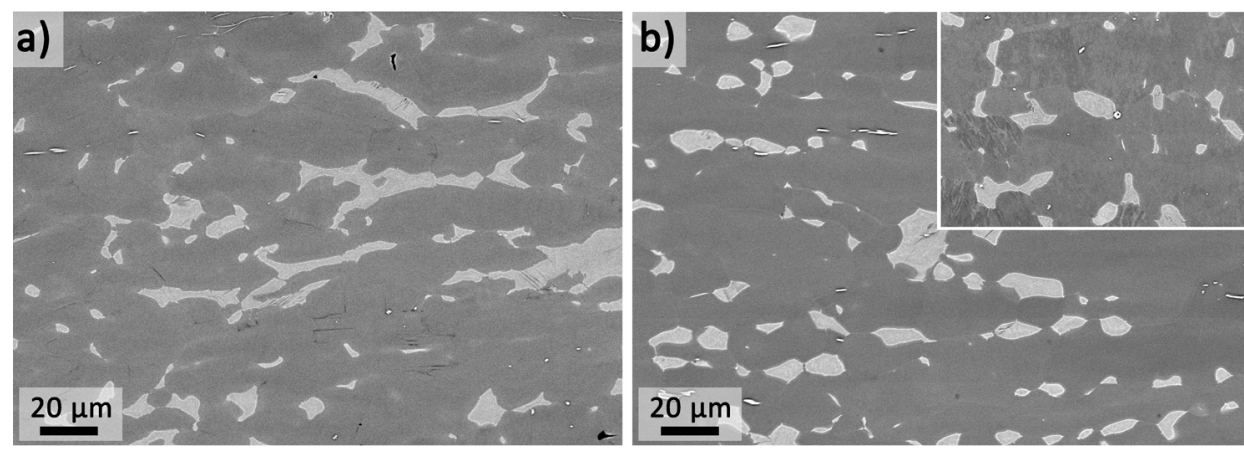

Fig. 3: Representative SEM images (BSE contrast) of the cast (a) and extruded (b) specimen after deformation. The compression axes are oriented vertically in both images. In the inset of (b), the extrusion direction is perpendicular to the image plane while it is parallel otherwise. Deformation parameters are indicated in Figures 4 and 5.

Stress-strain curves derived from the load and anvil displacement during the experiment are presented in Figure 4. Both specimens tested show a very similar development during deformation. At first, a small peak is observed before a constant (extruded specimen) or slightly decreasing (cast and HIPed specimen) flow stress is evident. The increase in stress before the experiments were terminated is attributed to the accompanying decrease in temperature (Figure 5). When comparing the two curves, it should be borne in mind that true stress and true strain were calculated by assuming that the shape of the specimen was preserved throughout the entire experiment. 
Fig. 4: Stress-Strain curves of the cast and the extruded TiAl specimen recorded during compression at $1300{ }^{\circ} \mathrm{C}$ at a strain rate of $0.00381 / \mathrm{s}$. Data obtained from the cast specimen are represented by triangles, those stemming from the extruded specimen are circles.

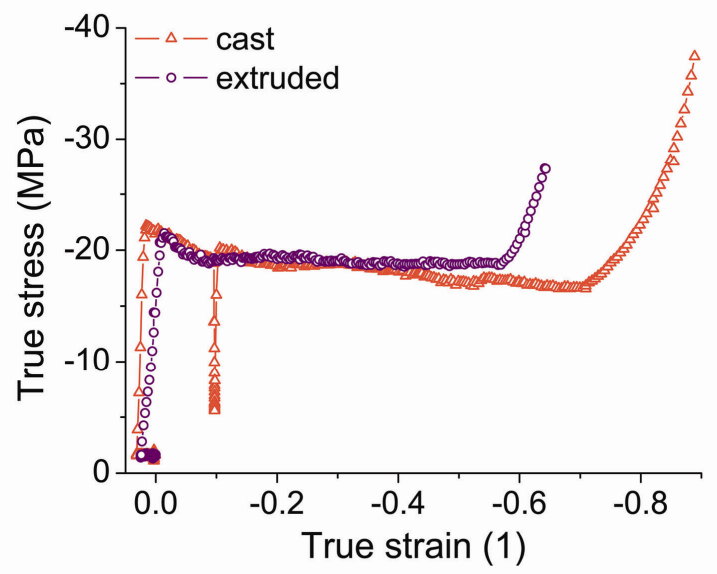

While this assumption is valid for small deformations, it becomes inaccurate for large strains since the specimen attains a barrel-like shape. Therefore, the small difference in the stress-strain curves can be assumed to be of no significance.

From the development of the diffraction patterns with time, details about the microstructural evolution can be derived. One way to display this development is a so-called AT-plot [4]. Here, the Intensity of a distinct reflection spot is plotted in grey-scale as a function of azimuthal angle and time. In Figure 5, AT-plots of the $\alpha 022$ and $\beta 002$ reflections are shown both for the cast and the cast and extruded material. Additionally, the parameters temperature, true strain, and true stress are shown in Figure 5c and $\mathrm{f}$.

The cast specimen reached a temperature of $1300{ }^{\circ} \mathrm{C}$ after $137 \mathrm{~s}$. Compression commenced at $\mathrm{t}=167 \mathrm{~s}$ (Figure 5c). At $\mathrm{t}=215 \mathrm{~s}$, deformation was discontinued until $\mathrm{t}=240 \mathrm{~s}$ to be able to observe the static behavior of the material at this temperature. Then, deformation continued until the experiment ended at $\mathrm{t}=439 \mathrm{~s}$. At $402 \mathrm{~s}$, a sudden decrease in temperature can be observed which apparently caused a corresponding increase in true stress. In the AT-plot of the $\alpha 022$ reflection (Figure 5a), the onset of compression is indicated by the occurrence of tilted traces of single reflection spots. In the following, these traces will be referred to as timelines. As deformation progresses, the timelines broaden and the AT-plot appears to be somewhat blurred. During the period in which deformation was stopped, the number of parallel timelines observed is higher than the one before deformation, which is indicative of grain refinement. In contrast to the $\alpha$-phase, the $\beta 002$ reflection shows the first changes already during holding at $1300{ }^{\circ} \mathrm{C}$. Timelines vanish and reflection dots appear which are indicative of phase transformations and recovery or recrystallization processes. Phase transformations are caused by the inequlibrium of phase fractions due to the high heating rates used. Furthermore, thermal stresses are generated during heating which may induce the occurrence of annealing phenomena. Upon deformation, the timelines broaden, but in contrast to the $\alpha$-phase timelines they attain a dotty appearance and are sharp. Additionally, the number of dots increases. During the time in which deformation was stopped, the $\beta$-phase timelines fluctuate which is in stark contrast to the $\alpha$-phase reflections and indicative of annealing phenomena such as recovery and recrystallization.

The cast and extruded specimen reached a temperature of $1300{ }^{\circ} \mathrm{C}$ after $135 \mathrm{~s}$ and started deformation at $165 \mathrm{~s}$ (Figure 5d). A maximum in true stress was attained at $\mathrm{t}=181 \mathrm{~s}$. At $350 \mathrm{~s}$ the temperature started to drop and at $\mathrm{t}=367 \mathrm{~s}$ the experiment was terminated. Figure $5 \mathrm{~d}$ shows that the $\alpha$-phase timelines start to fluctuate to some extent as soon as $1300{ }^{\circ} \mathrm{C}$ is attained. Static recovery and/or recrystallization occur to a small extent even before deformation starts. This is ascribed to the fact, that some energy of deformation is stored in the microstructure after the extrusion step which acts as a driving force for these processes. As soon as deformation starts, the timelines become tilted but no pronounced broadening of the reflections is evident. During deformation, the AT plot shows a number of inclined timelines which are visible for several tens of seconds. 


\section{cast}
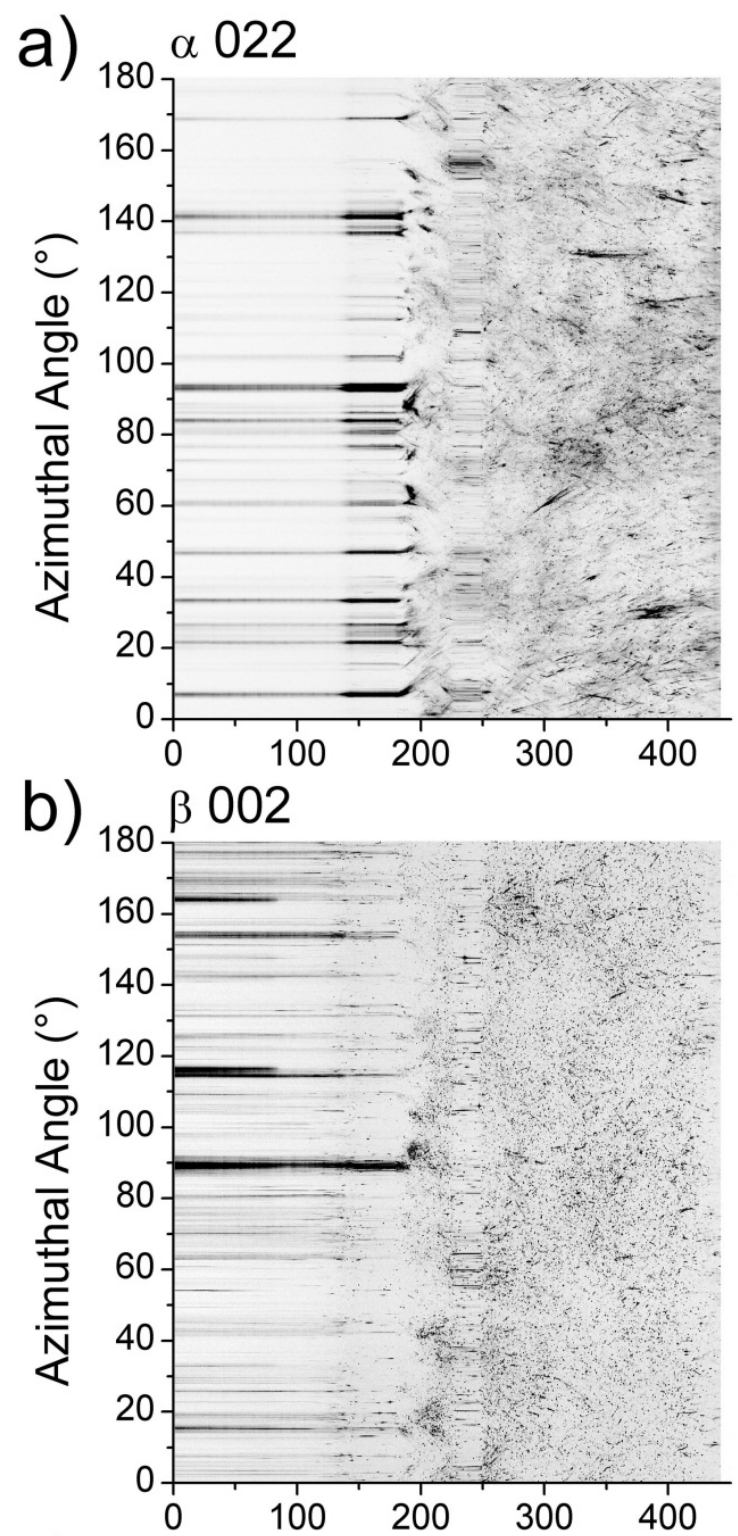

c)
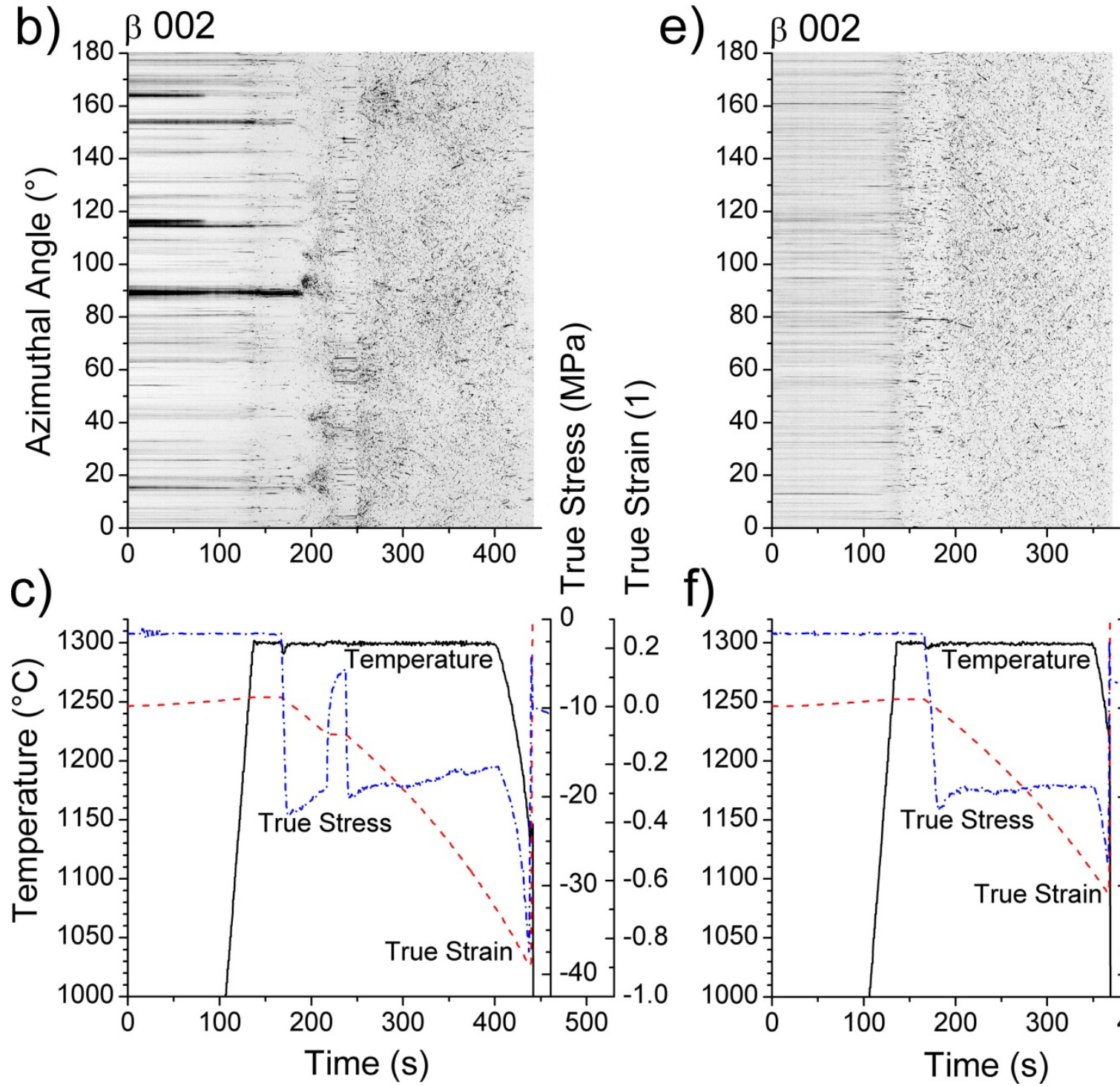

e)
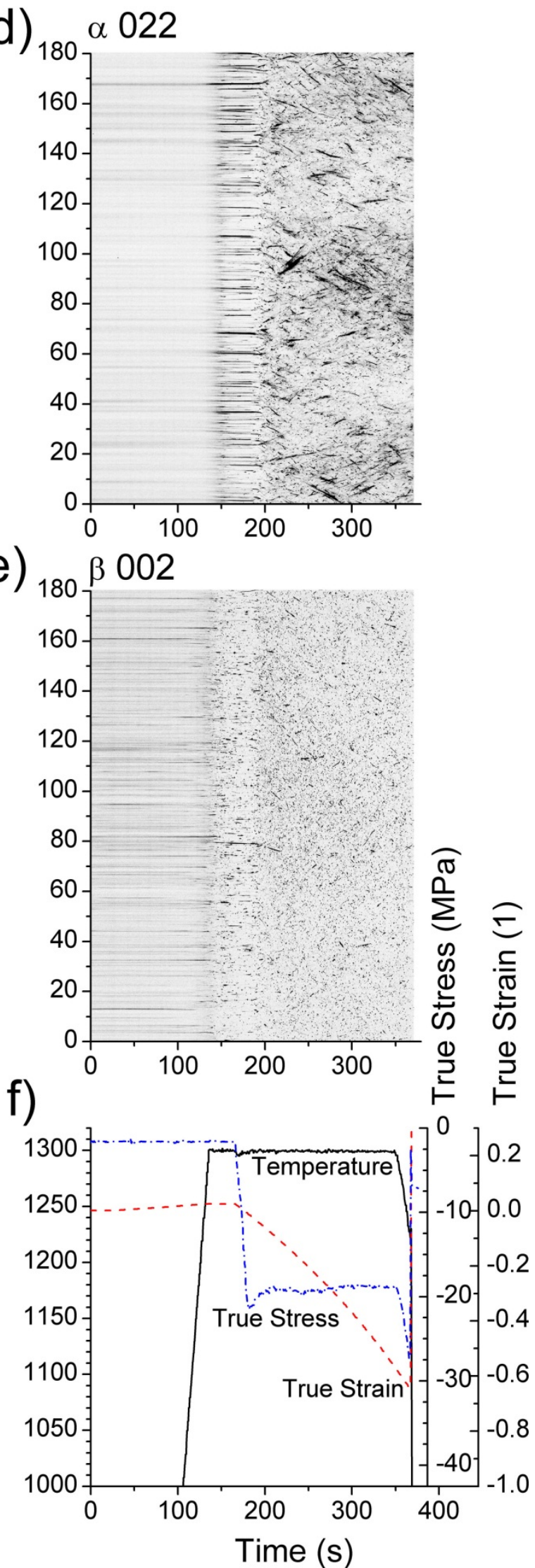

Fig. 5: Azimuthal angle-time (AT) plots for the $\alpha 022$ and $\beta 002$ reflections of the cast (a,b) and extruded $(\mathrm{d}, \mathrm{e})$ specimens. Additionally, temperature, true stress and true strain are indicated in the diagrams below (c, f). 
The $\beta$-phase shows timelines which start fluctuating rapidly at about $1300{ }^{\circ} \mathrm{C}$ which causes sharp dots to appear in the AT-plot. Upon deformation, the number of dots increases which indicates grain refinement. Data obtained by the in-situ diffraction experiment show that especially in the cast and HIPed specimen a significant refinement of the microstructure occurs. Broadening and even bifurcating of timelines provides evidences for the establishment of defect structures that can accommodate the plastic deformation imposed. At high temperatures, the $\beta$-phase is subjected to very high local strains due to its smaller flow stress compared to the $\alpha$-phase $[7,10]$. Therefore, grains rotate fast and cause sharp dots to appear in the AT-plot. Additionally, due to the high stacking fault energy which is associated with the bcc crystal structure of the $\beta$-phase, recovery processes can occur at high rates which keeps the defect density low causing the reflection dot to remain sharp. As deformation starts, little broadening of timelines is observed which is explained by the smaller starting grain size which facilitates the establishment of stable defect structures. Microstructural images support this interpretation of the synchrotron data and are also in accordance with the stress-strain curves obtained during the experiments.

\section{Summary}

High-energy X-ray diffraction was performed in-situ while compressing TiAl specimens at $1300{ }^{\circ} \mathrm{C}$. Additionally, scanning electron microscopic images of the microstructures before and after deformation were obtained. The cast and the cast and extruded specimens showed no significant differences in deformation behavior. It was shown that the finer grained extruded specimen started to recover and recrystallize at about $1300{ }^{\circ} \mathrm{C}$ and maintained a lower defect density during deformation. In the cast specimen only in the $\beta$-phase annealing phenomena occurred before deformation commenced. Furthermore, significant grain refinement took place during the compression experiment. In contrast to that, the extruded specimen coarsened which led to a similar grain size - and a similar microstructure - after deformation.

\section{Acknowledgement}

The Australian participants acknowledge travel funding provided by the International Synchrotron Access Program ISAP managed by the Australian Synchrotron. The ISAP is funded by a Collaborative Research Infrastructure Strategy grant provided by the Federal Government of Australia.

\section{References}

[1] Kim Y-W. Acta Metallurgica et Materialia 1992;40:1121-1134.

[2] Yamaguchi M, Inui H, Ito K. Acta Materialia 2000;48:307-322.

[3] Wu X. Intermetallics 2006;14:1114-1122.

[4] Liss K-D, Schmoelzer T, Yan K, Reid M, Peel M, Dippenaar R, Clemens H. Journal of Applied Physics 2009;106.

[5] Liss K-D, Yan K. Materials Science and Engineering: A 2010.

[6] Clemens H, Wallgram W, Kremmer S, Güther V, Otto A, Bartels A. Advanced Engineering Materials 2008;10:707.

[7] Wallgram W, Schmoelzer T, Cha L, Das G, Güther V, Clemens H. International Journal of Materials Research 2009;100:1021-1030.

[8] Tschentscher T, Suortti P. Journal of Synchrotron Radiation 1998;5:286-292.

[9] Daniels J, Drakopoulos M. Journal of Synchrotron Radiation 2009;16:463-468.

[10] Shi J.D, Pu Z, Zhong Z, Zou D. Scripta Metallurgica et Materialia 1992;27:1331-1336. 